Pelzer, August, Addenda et emendanda ad Francisci Ehrle Historiae bibliothecae romanorum pontificum tum Bonifatianae tum Avinionensis Tomum I, Vaticano 1947 (ND Modena 1981).

Puig i Oliver, Jaume de, Nicolau Eimeric. Diàleg contra els lul·listes, Barcelona 2002. Einführung und katalanische Übersetzung.

Roura Roca, Jaime, Posición doctrinal de Fr. Nicolás Eymerich OP en la polémica luliana, Gerona 1959.

\title{
Überlieferung:
}

Paris, BnF, lat.1464, 14./15. Jh., fol. 73r-96r (vgl. Heimann, 163-164).

Sevilla, Biblioteca Capitular y Colombina, 141-23-15, 14. Jh. (Ende), fol. 220-238 (vgl. Heimann, 166).

\section{R77. Frater Nicolaus de Spina?}

Legatio prophetarum ad Deum pro incarnatione Filii Dei

Disputatio sanctae Trinitatis super redemptione humani generis

Studie: Kapitel 7.

Incipit: Propter iniquitatem corripuit Deus hominem et quasi de limo [sic] in infernum dimersit... [Hs. Frankfurt]; Propter iniquitatem corripuisti hominem et quasi de sublimo in inferno dimersisti... [Drucke und Hs. Wolfenbüttel].

Explicit:... sicut novellae olivarum in circuitu mensae Domini saciabimur, apparente nobis gloria fructus ventris virginis benedictae, quod nobis ipse concedat, qui nos de nihilo creavit et suo sanguine pretioso redemit.

Autor: Der Titel der Frankfurter Handschrift schreibt den Dialog einem gewissen Frater Nicolaus de Spina zu. Ein Autor dieses Namens ist unbekannt.

Fassungen: Zwischen Drucken und Handschriften gibt es nur geringe Unterschiede. Meistens handelt es sich um kleine Verkürzungen oder stilistische Änderungen. Allerdings ist der Text in den Drucken um eine vollständige Szene, nämlich den Streit der Töchter Gottes, erweitert (zu diesem Motiv vgl. Mäder).

Datierung: Die Frankfurter Handschrift datiert den Text im Kolophon: Factus est tractatus iste anno domini $M^{\circ}$ cccxc. Diese Datierung ins Jahr 1390 scheint sich auf den Text selber zu beziehen und nicht auf die Niederschrift, die wohl etwas später entstanden ist. Es gibt keine Hinweise im Text, die eine Verifizierung dieses Datums erlauben, aber 
die allgemeine Ähnlichkeit mit den (allerdings viel knapperen) Schilderungen der Heilsgeschichte in den Eingangskapiteln der Meditationes de vita Christi und der Vita Christi des Ludolphs von Sachsen machen die Datierung in die 2. Hälfte des 14. Jhs. wahrscheinlich.

Inhalt: Der Text ist zum größten Teil als Dialog geschrieben, wird aber häufig von narrativen Abschnitten unterbrochen, die die Handlung voranbringen. Der Weg zur Erlösung wird geschildert, wobei Motive aus der Bibel, theologische Reflexion und sagenhafte Elemente vermischt werden.

In einer narrativen Einführung wird geschildert, wie der Teufel den Menschen zur Sünde verführt und dadurch Macht und Besitzrecht über ihn gewinnt. In der babylonischen Gefangenschaft (hier wohl eine Metapher für die Vorhölle) beklagen die Gerechten ihr Schicksal, während der Teufel sie, seines Sieges sicher, auslacht. Die Gerechten beschließen, nacheinander vier Botschafter in den Himmel zu schicken, um in ihrem Namen Gott anzuflehen, sie zu erlösen. Als Gesandte werden Isaias, Jeremias, Hiob und Daniel gewählt. Die Kapitel über diese vier Gesandtschaften sind alle nach dem gleichen Muster aufgebaut: zuerst hält der Botschafter eine Rede, die von Gott ablehnend erwidert wird, dann kehrt er in die Vorhölle zurück und beklagt seinen Misserfolg. In einer neuen Versammlung beschließen die Gerechten, eine Jungfrau zu suchen, für deren Liebe Gott bereit wäre, der Menschheit wieder wohlgesonnen zu sein. David geht in den Himmel und wird von einem Engel aufgehalten, den er um Beistand anfleht. Der Engel ersucht Gott darum, David zu empfangen. David bittet um Hilfe und Gott erwidert, sein Volk müsse Heim und Synagoge zuerst verlassen, er zeigt sich aber dem Anliegen der Gerechten wohlgesonnen. [An dieser Stelle wird in den Drucken der Streit der Gottestöchter Justitia, Veritas, Misericordia und Pax geschildert. Die Verbindung zwischen beiden Motiven, dem Rat der Trinität über die Erlösung der Menschheit und dem Streit der Töchter Gottes, ist seit dem 12. Jh. belegt, vgl. Ohly. Zuerst spricht Misericordia für die Menschheit und Veritas dagegen. Als Veritas dann schwach wird, schaltet sich Justitia ein und verlangt die Strafe der Menschheit. Ein Judex meldet sich zu Wort und sagt, nur ein guter Tod, das heißt, der freiwillige, unverdiente Tod eines Gerechten, könne die Menschheit befreien und den Gottestöchtern Genüge tun. Misericordia und Veritas suchen in der ganzen Welt nach einem Gerechten und finden keinen. Pax sagt, der Judex selbst müsse das Opfer sein. Als er das hört, bestätigt er, den Menschen geschaffen 
zu haben und deswegen für seine Verfehlung mitverantwortlich zu sein]. David überbringt die gute Nachricht, ruft die gewählte Jungfrau zu sich und ermahnt sie. Sie wird zu Gott geschickt und findet sein Gefallen. Gott entsendet den zweifelnden Gabriel zu Maria. Nach der Ankündigung Gabriels schwankt Maria, sie wird jedoch von den Patriarchen ermutigt und akzeptiert schließlich ihre Mission. Die Dreifaltigkeit berät darüber, welche der drei Personen Fleisch werden soll, der Sohn bietet sich an und wird geboren. Dann kommen die Patriarchen zum Kind. Als sie es so klein sehen, werden sie unsicher, ob es seinen Auftrag wird erfüllen können. Jesus beruhigt sie und sagt, er sei imstande, den Teufel zu besiegen. Sein Volk, die Juden, hält ihn deswegen für hochmütig und wendet sich von ihm ab. Deswegen lässt er den Sündern und Fremden seine Gnade zukommen. Als der Teufel davon erfährt, wird er unruhig. Die anderen Teufel äußern die Vermutung, Jesus könne Gott sein, die Idee wird aber als zu abwegig abgelehnt. Lazarus verlässt die Hölle, als er von Jesus gerufen wird. Der Teufel geht zum Himmel und beschwert sich darüber. Der Sohn setzt sich jedoch für Lazarus ein und der Teufel willigt ein, eine Ausnahme zu machen. Er ist jedoch so verblendet, dass er Jesu wahre Identität immer noch nicht erkennen kann. Mit dessen Tod verliert der Teufel seine Macht über die Gerechten, die daraufhin die Vorhölle verlassen. Die Teufel beklagen den Verlust ihrer Macht. Maria sucht indessen ihren Sohn, und als der Auferstandene ihr erscheint, bittet sie ihn um die Vergebung der Sünden für alle, die sie lieben und ehren. Jesus befiehlt seinen Jüngern, weiterhin gegen den Teufel zu kämpfen. Dann steigt er zum Himmel auf, wo er vom Vater aufgenommen wird, während der Heilige Geist auf die Jünger herabkommt. Jesus bittet den Vater um einen neuen Versuch, die Juden zu retten. Die Apostel werden deswegen ausgesandt, sie werden aber von den Juden getötet. Daraufhin beschließt der Vater, die Heiden in das Gottesvolk aufzunehmen. Das Werk endet mit einer Schilderung des Jüngsten Gerichts, der Wehklage der Verdammten und der Freude der Gerechten.

\section{Literatur:}

Mäder, Eduard Johann, Der Streit der „Töchter Gottes“. Zur Geschichte eines allegorischen Motivs, Bern - Frankfurt 1971.

Ohly, Friedrich, „Die Trinität berät über die Erschaffung des Menschen und über seine Erlösung“", Beiträge zur Geschichte der Deutschen Sprache und Literatur 116 (1994), 242-284 (die Legatio prophetarum wird nicht berücksichtigt).

Edition: Unediert. 